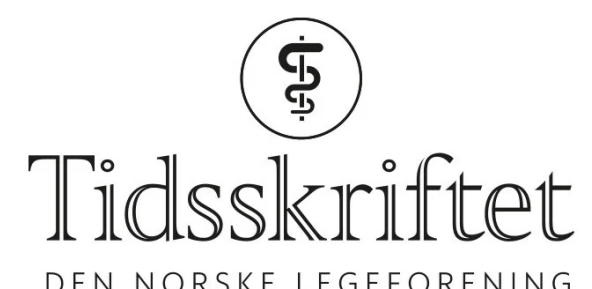

DEN NORSKE LEGEFORENING

\title{
En annen dans
}

INTERVJU

ANNE KATHRINE SEBJØRNSEN

annekaths@hotmail.com

Brit Havers engasjement for kvinner med alkoholproblemer våknet allerede i barndommen. Det ledet til den første doktorgraden i psykiatri ved Universitetet i Bergen levert av en kvinne, praksisendrende forskning og Kongens fortjenstmedalje. Nå er hun aller mest opptatt av hva slags verden barnebarna skal vokse opp i.

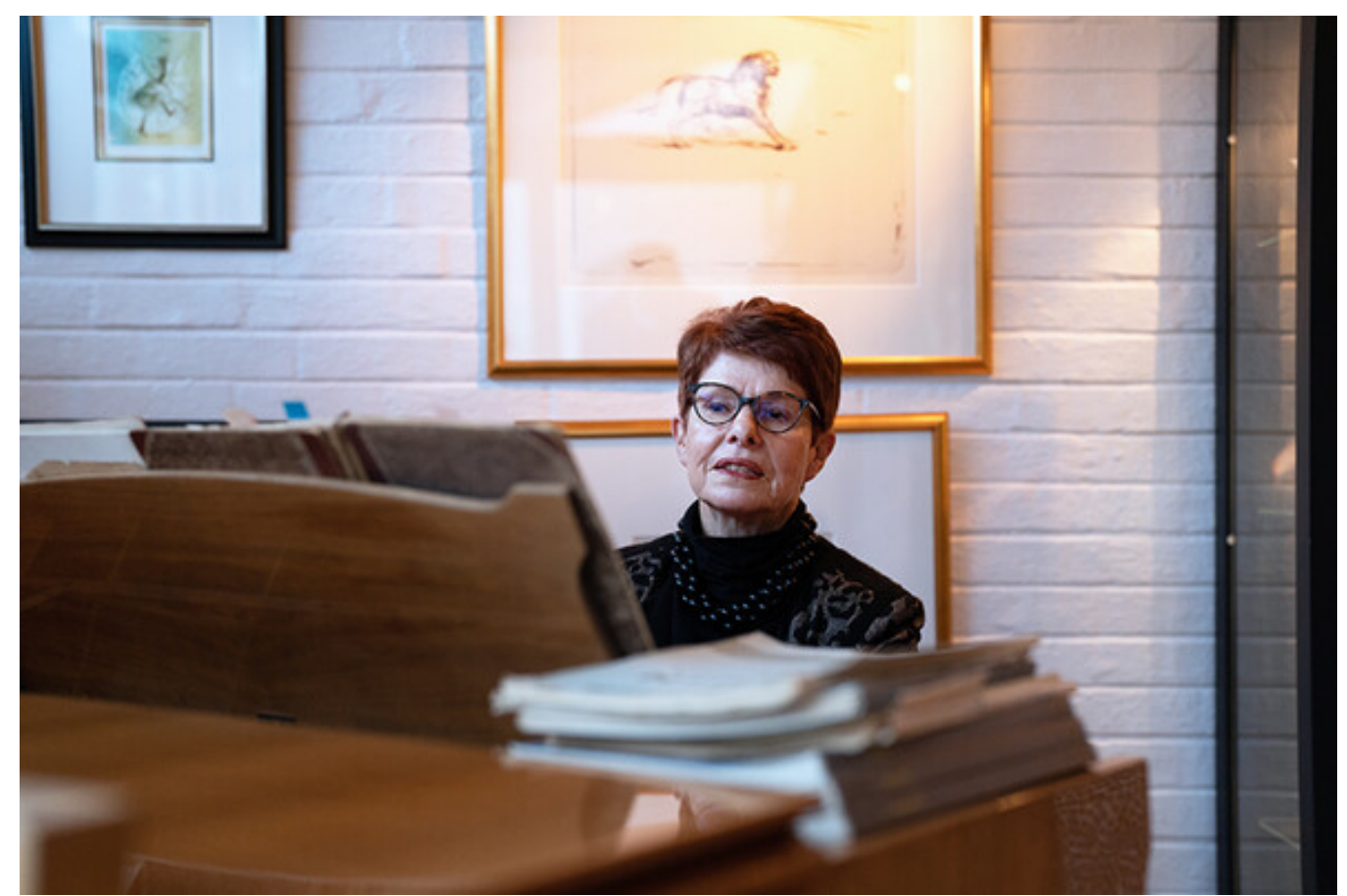

Foto: Magne Sandnes

Den massive døren inn til ærverdige Lorry går sakte opp. Inn fra kulden trer en elegant dame i vinterkåpe med pelskrage og høyhælte støvletter, ubestemmelig i alder, men fortsatt lettbent som en ballerina. Professor Haver ved Institutt for klinisk medisin ved Universitetet i Bergen synes det er viktig å fiffe seg opp litt. Man vet tross alt aldri hvem man treffer på. 
Som den vinterdagen i 1962, da den unge studinen fra bergenskullet falt så lang hun var i skisporet i Nordmarka og så rett inn i en blå anorakk og et par milde øyne hun raskt gjenkjente. «Må jeg få hjelpe Dem opp, frøken», sa Hans Majestet Kong Olav, og rakte henne en vottekledd hånd. Inntil da hadde hun vært lite begeistret for kjølige og avmålte oslofolk, og spesielt skeptisk var hun til de fine «frognerfruene» i nabolaget.

«Takk», stotret hun mens Kongen dro henne opp, og hun forsto at fra nå av ville nok hjertet banke for både Kongen, Nordmarka og hovedstaden.

- Jeg lå i en ytterst ubehagelig stilling, og var svært takknemlig for hjelpen. Det var første gang at noen sa «De» til meg, jeg som bare var en jentunge. Jeg glemmer det aldri, sier hun, med trykk på aldri.

\section{Damen og gutten}

Brit Haver takker høflig nei til servitørens tilbud om vin til maten.

- Jeg unngår ikke alkohol, men jeg forsøker å leve som jeg lærer, med en slags bevissthet rundt det. Jeg skal i middag senere i kveld, og trenger ikke alkohol for å ha det hyggelig, sier hun med myk stemme.

Forsiktig og mild i formen, men krystallklar og bestemt. Haver er en dame som vet hva hun vil. De siste syv årene har hun påtatt seg oppdrag som overlege i psykiatrien i tillegg til å være en aktiv professor. Det er altså ikke så mye tid til å være pensjonist. Og hvorfor skal man det, når det er så mye å ta tak i på denne skjeve kloden? Hun har alltid hatt for vane å stupe inn i det andre unngår. Tabuene, de som sliter og har lav status. Det er for dem hjertet slår fortest.

\section{Brit Haver}

Født 1942

Medisinsk embetseksamen ved Universitetet i Bergen (UiB) 1967

Spesialist i psykiatri 1975

Overlege Blå Kors Sosialbygg, Bergen 1976-1981

NAVF-stipendiat ved Center of Alcohol Studies, Rutgers University, New Jersey, USA 1986-87

Dr.med. ved UiB på avhandlingen Outcome of alcoholism in women. A follow-up study of 55 women 3-10 years after treatment 1988

Gjesteforsker ved Karolinska Institutet, Institutionen för klinisk neurovetenskap, Stockholm 1991-94

Førsteamanuensis og professor ved Institutt for klinisk medisin, UiB, og overlege ved poliklinikk for affektive lidelser, Haukeland universitetssjukehus 1997-2013

Kongens fortjenstmedalje for forskning, undervisning og behandling av kvinner med alkoholproblemer 2015

Forfatter av bøkene Bipolare lidelser (red. og medforfatter), Fagbokforlaget 2012, og Hva gikk galt hos legen? Når dialogen svikter, Spartacus forlag 2016

Brit Havers livslange engasjement for de mest utsatte og utstøtte kvinnene begynte allerede under oppveksten i Stavanger.

- Rett over gaten for mitt barndomshjem i Stavanger bodde tante Inga. Hun hadde et stort og vedvarende engasjement for kvinner som ble alkoholiserte, og jeg fulgte interessert med på aktiviteten hun drev for disse kvinnene etter krigen. Noen av dem var såkalte 
tyskertøser, som fikk det tøft i etterkrigstiden, særlig hvis de også hadde et såkalt tyskerbarn, forteller hun.

Ved hjelp av en donasjon fra bokhandler Carl Bang, og en formidabel egeninnsats, stiftet Inga «Kontaktheimen». Der fikk kvinnene husly, mat og hjelp. Inga hadde ikke noen formell kompetanse innenfor hverken rusproblematikk eller helse, men derimot en utrettelig omsorg for de sårbare kvinnene. En av kvinnene ble ansatt som hushjelp hos tanten.

- Denne damen hjalp til i tantes hus, og vi pleide å leke med sønnen hennes i gaten. Hun pleide å forsvinne i lengre perioder. Det tok en stund før jeg forsto at damen drakk når hun ble borte, erindrer Haver.

Hun renser stemmen.

- På den tiden kunne "edruelighetsnemnden" plassere folk i fengsel for beruselse eller drikking på offentlig sted. De kunne sone lenger enn mordere, sier hun og rister på hodet. $\emptyset$ nsket om å hjelpe disse kvinnene var vekket. Atten år gammel dro hun til Oslo for å begynne på medisinstudiet.

\section{Ingen kvinnelige rollemodeller}

Haver var én av fire kvinner blant i alt førti studenter på bergenskullet i 1961.

- Det fantes ingen kvinnelige rollemodeller for oss, men vi fire holdt tett sammen. Jeg så én kvinnelig lege som underviser i løpet av hele studiet.

«Kommentarer som 'Har de begynt å sende ut skolejenter nå?' var ikke helt uvanlig»

I turnus på Radøy var hun og mannen en aldri så liten sensasjon, han trillende på barnevogn, hun travelt opptatt med inntil sytti pasienter på en dag.

- Jeg var 49 kilo lett og så veldig ung ut, og kommentarer som «Har de begynt å sende ut skolejenter nå?» var ikke helt uvanlig, forteller hun.

- En gang ringte det en mann på natten og krevde å få snakke med «Han sjøl». Da sa jeg at det måtte han gjerne, men at mannen min ikke var doktor, men lektor. De forestilte seg ikke at en kvinne kunne gjøre legejobben, sier hun og humrer.

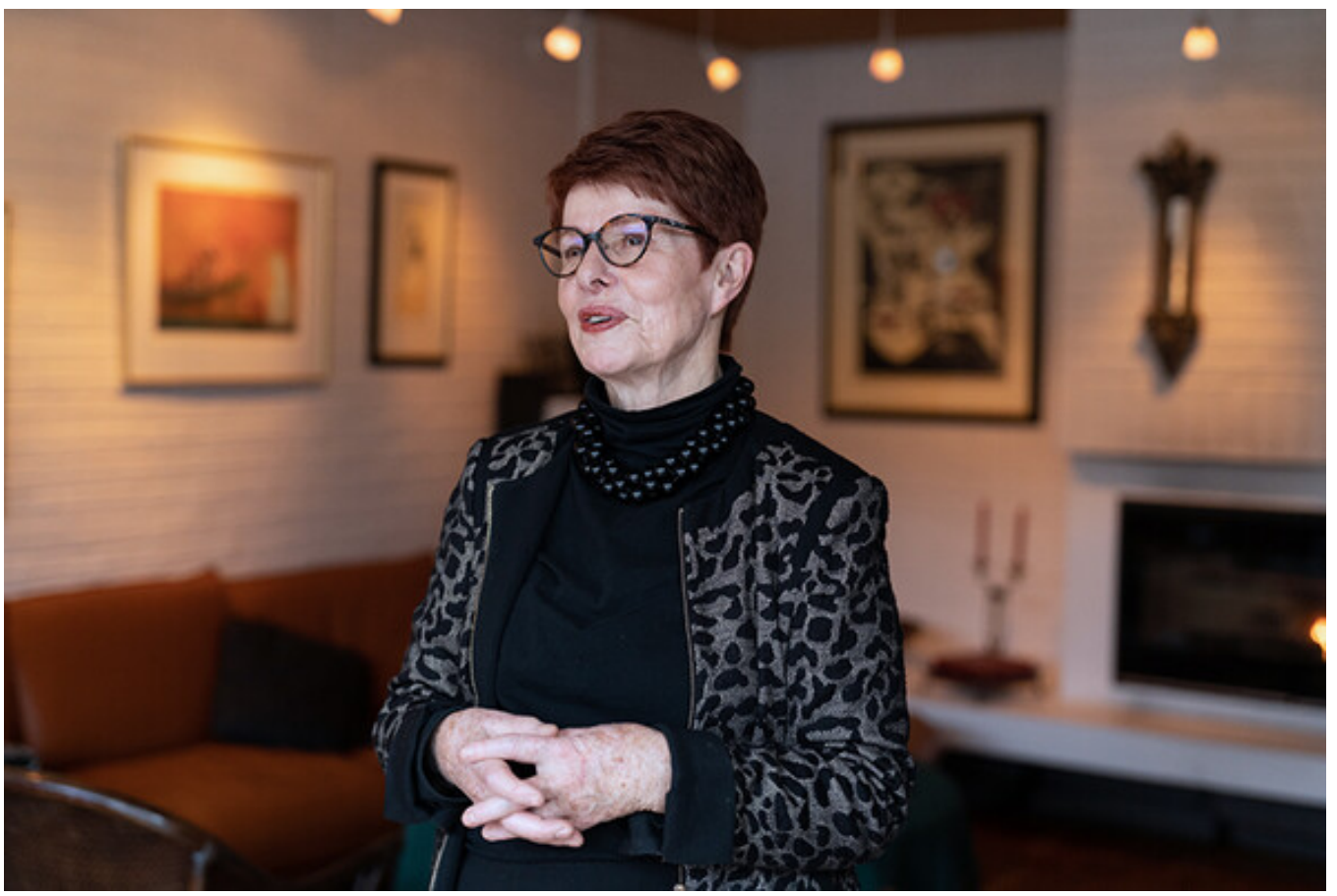


Foto: Magne Sandnes

Interessen for psykiatri startet under studietiden i Oslo. Riktignok ville pianolæreren ha henne til å satse på en karriere som pianist, men det passet ikke så bra for en som hverken likte å øve eller å spille foran andre.

- Det blåste en "psykiatrivind» på dette blandingskullet av studenter opptatt ved Universitetet i Oslo og Universitetet i Bergen i 1961. Svein Haugsgjerd, som senere ble psykiater og ga ut skjellsettende psykiatribøker, hadde gruppemøter for interesserte kullinger. Mange av studentene som deltok der, møtte jeg senere igjen ved nasjonale konferanser innen psykiatri. Jeg vil påstå at det var uvanlig mange som ble psykiatere og barne- og ungdomspsykiatere på dette kullet, sier hun og lyser opp.

\section{Rakhmaninov og Elvis}

- Hadde du noen kvinnelige rollemodeller innenfor fagfeltet som inspirerte deg?

- Jeg kan faktisk ikke huske at jeg på det tidspunktet ble inspirert av noen kvinnelige psykiatere. I psykiatriundervisningen var det bare mannlige forelesere, og jeg så bare mannlige psykiatere på utdanningsstedene. Først da jeg selv var utdannet psykiater, var det en del kvinner som ble mine forbilder.

Hun trekker frem Sonja Vaglum og Astrid Heiberg som de fremste blant disse, samt svenske Lena Dahlgren, stifteren av det såkalte EWA-prosjektet (Early Treatment of Women with Alcohol Addiction).

- Jeg deltok selv i dette prosjektet i tidsrommet 1991-94 i Stockholm, som klinisk forsker. I disse dager publiseres den siste i en lang rekke av 25 års oppfølgingsstudier av dette pasientmaterialet. Materialet er unikt i verdenssammenheng, sier hun stolt.

Hun smiler, takker høflig servitøren som rydder av bordet.

- Heldigvis var det fem unge kvinner som begynte i spesialisering i psykiatri omtrent samtidig med meg i Bergen. Vi var en gruppe reserveleger som jobbet på de samme institusjonene og dro på årsmøter sammen. Etter spesialiseringen valgte vi svært ulike retninger innen psykiatri, men vi holdt alltid sammen og gjør det fortsatt den dag i dag, forteller hun.

«Ingen hadde tenkt på at det også var kvinner blant rusmisbrukerne, så det fantes ikke noe eget avsnitt for dem»

Selv om det ikke ble noen pianistinne av henne, er hun ikke dårligere enn at hun fortsatt lar fingrene leke seg over tangentene med alt fra Chopin til Beethoven, Rakhmaninov og Brahms når anledningen byr seg.

- Og så elsker jeg Elvis Presley, det må du få med! Jeg elsker alt av musikk, utbryter hun og tripper litt med foten.

- Jeg er med i en klubb som spiller klassisk musikk i Bergen. Vi har snart femtiårsjubileum, men nå er vi bare seks igjen, dessverre.

Hun trekker jakken tettere omkring seg. Kulden sniker seg inn gjennom dørgløttet hver gang gjester kommer og går.

\section{De glemte kvinnene}

Som ferdig spesialist begynte hun som overlege på et nyåpnet Blå Kors Sosialbygg. 
- Institusjonen var tenkt å skulle løse de fleste problemer, slik at man kunne nedlegge drukkenskapsarresten, håpet politiet. Ingen hadde tenkt på at det også var kvinner blant rusmisbrukerne, så det fantes ikke noe eget avsnitt for dem i nybygget. Vi så at de var sårbare for utnyttelse, men det fantes veldig lite forskning på alkoholmisbruk blant kvinner. Det var et tabu, og det var lavstatus. Jeg startet studien som ble min doktorgradsavhandling der. Forskningen min bidro til at alkoholbruk blant kvinner ble omtalt og hensyntatt, og det bidro til at man endret behandlingsopplegg. De fem årene jeg hadde der, var en av de mest interessante periodene i mitt liv, understreker hun.

\section{«De sykeste pasientene får sannsynligvis det minst adekvate behandlingstilbudet»}

Senere fulgte hun dette forskningsfeltet opp ved EWA-enheten i Stockholm, det første spesialiserte behandlingsopplegg for kvinner med alkoholavhengighet, så tidlig som mulig i misbrukskarrieren.

I 2015 fikk hun Kongens fortjenstmedalje for sin iherdige innsats for forskning, undervisning og behandling av kvinner med alkoholproblemer.

\section{Underskogen minker}

Det var stor optimisme i psykiatrien da Brit Haver startet i spesialisering for femti år siden. Ny medikasjon og ulike former for psykoterapi skulle revolusjonere faget. Nå er hun alvorlig bekymret for fagets fremtid.

- Krisen i psykiatrien er en lenge varslet katastrofe. Det har over tid vært en alvorlig underfinansiering av feltet i tillegg til en altfor stor reduksjon i sengeplasser. Allerede tiår tilbake så man en mangel på psykiatere, en tendens som økte på i forbindelse med etableringen av distriktspsykiatriske sentre over hele landet. Første gang jeg sa fra om dette i Helsedirektoratet, var for tretti år siden. Da var svaret at "psykiaterne får smøres tynt utover!».
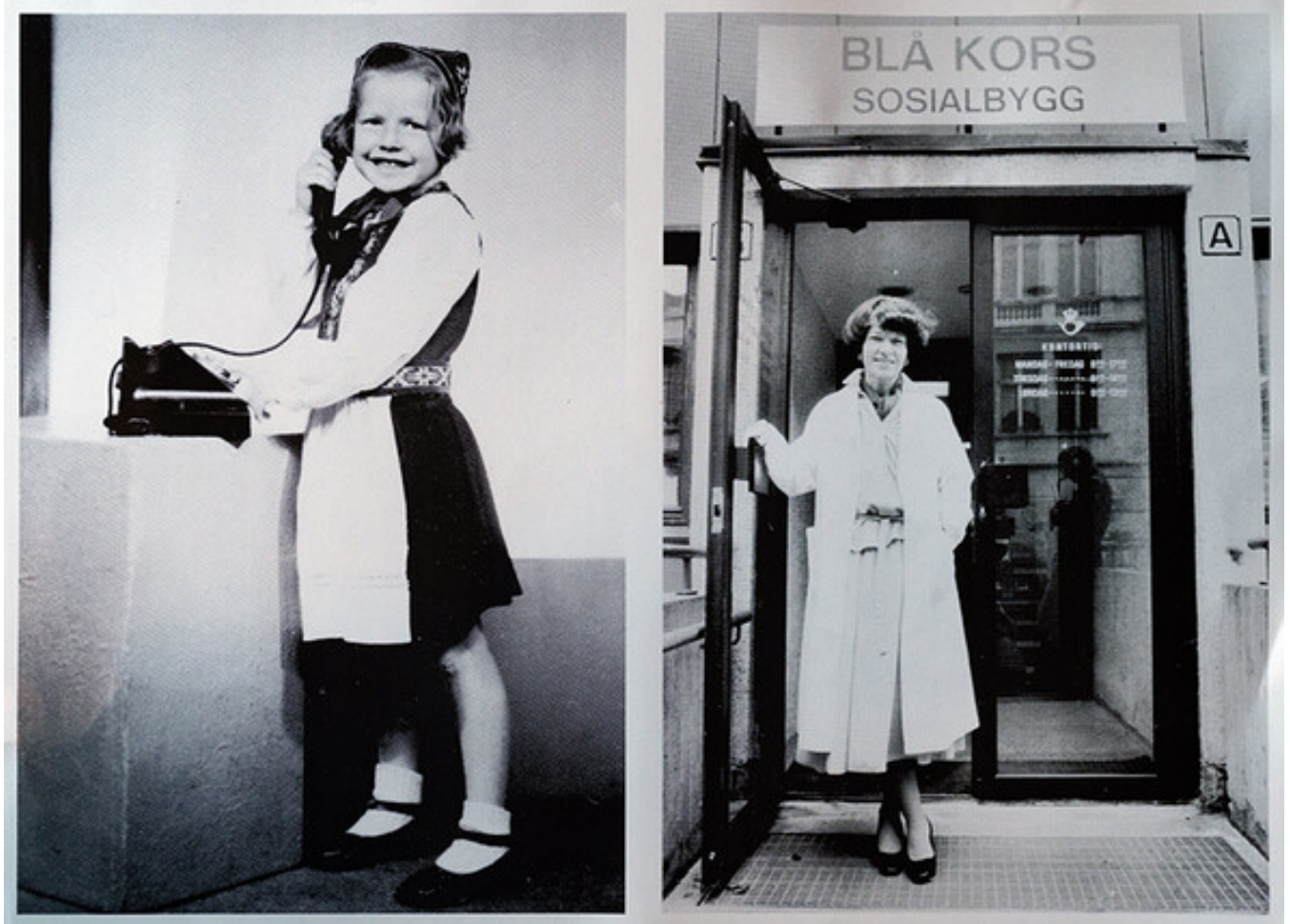

Foto: Privat

Brit Haver er tydelig oppgitt, og forteller at hun er bekymret på pasientenes vegne. 
- Det er som om sentrale helsemyndigheter ikke har forstått at noen pasienter med psykiatriske lidelser vil ha behov for livslang behandling og oppfølging. Slike pasienter går nå i en evig runddans mellom ulike institusjoner og forskjellige kategorier av behandlere, med veksling mellom kommunale tjenester og kortvarige opphold innen spesialisthelsetjenesten. De sykeste pasientene får sannsynligvis det minst adekvate behandlingstilbudet. Den reelle opptrappingsplanen for psykiatrien kom aldri, sier hun.

\section{Utvanning av psykiaterrollen}

Nå er hun redd psykiaterrollen utvannes eller til og med forsvinner med tiden.

- Jeg fikk en solid psykiaterutdannelse innen biologisk psykiatri, psykoterapi og forskning som jeg har tviholdt på gjennom årene. Psykiaterne er krumtappene i behandlingen av enhver psykiatrisk lidelse, men rekrutteringssvikten har ført til at de altfor få psykiaterne man fortsatt har, faktisk «smøres tynt utover». Færre søker seg til psykiatrien, underskogen minker. Psykiaterne må ta ansvar for veldig mange pasienter som ikke er ens egne når det kommer til somatikk fordi psykologer, sykepleiere og folk med annen faglig bakgrunn ikke har kompetanse til å ivareta den delen av behandlingen, sier hun.

Hun er redd leger vil slutte å søke seg til psykiatrien hvis denne utviklingen fortsetter.

- Vil leger med fremtiden foran seg investere i å bli «medisindoktere» for andre kategorier av helsepersonell? Er det riktig at en pasient henvist til spesialisthelsetjenesten knapt nok undersøkes av en psykiater? Man kan spørre seg om forsvarligheten i det, sier hun retorisk.

Likevel vil hun absolutt ikke fraråde unge leger å velge psykiatri.

- Psykiatri er en flott spesialitet med mange flotte kolleger og meningsfulle pasientmøter, understreker hun.

\section{Rebell i kveld}

Brit Haver har ikke på noen måte satt seg til rette i gyngestolen og synes absolutt ikke det er noen grunn til å roe ned selv om hun går inn i sitt åttiende år. Tvert imot er det all grunn til å engasjere seg for kloden og de som kommer etter.

Siden stiftelsen av Besteforeldrenes klimaaksjon i 2009 har hun vært aktiv både som medlem og i styret. Hun synes det er deilig å være rebell for noe hun tror på.

\section{«Det er all grunn til å engasjere seg for kloden og de som kommer etter»}

- Jeg deltok på en uforglemmelig klimamarsj i New York i 2013, sier hun. Stemmen løfter seg et par oktaver.

- Ikke ett fly i luften eller én bil i gatene. Det var «linet» med politikvinner og -menn, smilende, men med pistoler, selvsagt - for sikkerhets skyld, sier hun med dyp innlevelse.

- En halv million mennesker, og knapt en lyd å høre da klimabrølet startet et sted langt borte og spredte seg gjennom det endeløse gateløpet, forsterket av ekkoet skapt av skyskraperne omkring.

Hun setter øynene i meg.

- Vi trodde at dette brølet ville bli hørt, men neida, skravler hun på sin særegne stavangersk-bergenske dialekt.

- Det måtte en liten jente fra Sverige til!

Hun tar en kort pustepause. 
- Etter denne marsjen kom jeg utmattet og med verkende ben til mine barnebarn i New Jersey. Det var for dem jeg gikk denne lange marsjen den søndagen. Jeg er forresten også medlem av Legenes klimaaksjon pluss en rekke andre organisasjoner som arbeider for fred og kvinner.

Hun tenker seg litt om. Blir drømmende i blikket.

- Hvis jeg var ung nå, ville jeg blitt danserinne. Hvor lett kunne ikke livet blitt? Hun gjør en grasiøs bevegelse.

- Sportsdans eller selskapsdans. Jeg elsker å danse! I fantasiens verden kan man jo male de fargene man vil, det er det som er så fint.

Hun kaster et lengselsfullt blikk mot utgangsdøren.

- Hvor finner jeg en taxi som kan ta meg til sentrum?

Brit Haver har allerede reist seg, kåpen og skjerfet er virvlet omkring henne. Hun har hastverk. Hun er invitert på middag hos en venninne i tyveårene på Grünerløkka. På lette ben gjør hun noen nesten umerkelige dansetrinn. Før Oslo Taxi rekker å svare, har Brit Haver praiet en drosje som stoppet på rødt lys i Parkveien. Den elegante kåpen flagrer inn i bilen rett før lyset skifter til grønt. Kvelden er ennå ung, og man vet jo aldri hva den bringer.

Publisert: 27. januar 2022. Tidsskr Nor Legeforen. DOI:10.4045/tidsskr.21.0853

(C) Tidsskrift for Den norske legeforening 2023. Lastet ned fra tidsskriftet.no 26. april 2023. 